\title{
Association of Rs61764370 polymorphism within let-7 microRNA-binding site with lung cancer in Iranian population
}

\author{
Neda Farokhzad, Sayed Mostafa Hosseini, Houri Edalat, Morteza Sadeghi
}

Human Genetics Research Center, Baqiyatallah University of Medical Sciences, Tehran, Iran.

\section{Author details:}

Neda Farokhzad: nedafarokhzad@gmail.com Tel: 00982188930659; Sayed Mostafa Hosseini: smhosseini@bmsu.ac.ir Tel : 00982188930659; Houri Edalat: hs97782@yahoo.com Tel : 00982188930659

\begin{abstract}
Introduction: Polymorphisms within miRNAs binding sites are associated with miRNAs function. The aim of this study was to investigate the relationship between rs61764370 polymorphism within let-7 miRNA binding site in KRAS gene and the risk of lung cancer in Iranian population.

Methods: This case-control study was conducted with 100 lung cancer patients and 100 healthy persons. The rs61764370 polymorphism was analyzed using PCR-RFLP technique and direct sequencing.

Results: We found a significant relationship between rs61764370 (T / G) polymorphism and lung cancer risk, the GT genotype (OR: 6.25; 95\% CI = 2.605-15.00; $\mathrm{P}=0.000)$ and $\mathrm{G}$ allele (OR: 5.25; 95\% $\mathrm{CI}=2.259-12.208 ; \mathrm{P}=0.000)$ were significantly associated with an increased risk of lung cancer.

Conclusion: According to our findings, there is a significant relationship between the KRAS rs61764370 polymorphism and lung cancer risk in Iranian population and this polymorphism may be used as a marker in detection of lung cancer in the future.

Keywords: Polymorphism, KRAS, lung cancer, Let-7.

DOI: https://dx.doi.org/10.4314/ahs.v20i3.35

Cite as: Farokhzad N, Hosseini SM, Edalat H, Sadeghi M. Association of Rs61764370 polymorphism within let-7 microRNA-binding site with lung cancer in Iranian population. Afri Health Sci. 2020;20(3): 1299-1303. bttps:/ / dx.doi.org/10.4314/ ahs.v20i3.35
\end{abstract}

\section{Introduction}

Lung cancer is one of the most common cancers in the world, and more than $80 \%$ of patients with lung cancer die within the first five years after diagnosis. The two major types of lung cancer are small cell lung cancer (SCLC), which accounts for about $20 \%$ of patients with lung cancer, and non-small cell lung cancer (NSCLC), which accounts for the other $80 \%$ of patients ${ }^{1,2}$. Environmental factors and genetic factors are two main risk factors of lung cancer. Identification of molecular markers for early diagnosis of this disease can be effective in decreasing the mortality rate and patients treatment ${ }^{3}$. The KRAS gene is one of the most im-

\section{Corresponding author: \\ Morteza Sadeghi, \\ Human genetics Research Center, Baqiyatallah \\ University of Medical Sciences, Tehran, Iran. \\ Tel : 00982188930659 \\ Email address: Ms.sadeghi@yahoo.com}

portant human oncogenes that span/play an important role in MAPK signaling. KRAS mutations, particularly mutations in the regulatory region of this gene, can increase the expression of this gene and are associated with various human cancers including lung cancer ${ }^{4-5}$. MicroRNAs are a group of non-coding RNAs of about 25-18 nucleotides in length, which play important roles in gene regulation, they can change the expression of the target gene by coupling with their complementary regions in the miRNA of target gene ${ }^{6}$. MicroRNAs regulate about $60 \%$ of all coding genes and play important roles in many biological processes including proliferation, differentiation, development, cell death and cancer 7. Single-nucleotide polymorphisms (SNPs) located in the KRAS promoter region within miRNA binding site can regulate the KRAS gene expression ${ }^{8}$. A single-nucleotide polymorphism (T/G) rs61764370 within the binding site of let-7 miRNA in the KRAS 3'UTR region cause change in the expression of this gene ${ }^{9,10}$. A number of recent studies have shown that rs61764370 polymorphism is associated with an increased risk of 
different cancers, including ovarian cancer, cervical cancer, breast cancer, colorectal cancer, and lung cancer ${ }^{11}$ ${ }^{15}$. In a study on tissue and blood samples in Italy and United States, Ratner et al. reported that there is a significant relationship between rs61764370 and ovarian cancer; they span described this polymorphism as an ovarian cancer genetic marker ${ }^{16}$. On the other hand, some studies reported no association between this polymorphism and cancer. In a study on the Norwegian population, Kjersem et al. reported no significant relationship between rs61764370 polymorphism and colorectal cancer ${ }^{17}$. Luong et al. did not find a significant relationship between rs61764370 polymorphism and uterine cancer in Australia ${ }^{18}$. Considering the importance of KRAS gene and Let- 7 in the development of cancers, we decided to investigate the association between this polymorphism and lung cancer risk in the Iranian population in this study.

\section{Materials and methods: \\ Sample collection}

This case-control study included 100 patients with lung cancer and 100 healthy individuals. The patient group included patients with lung cancer who had referred to Maseeh Daneshvari Hospital in Tehran from 2017 to 2018. The control group consisted of healthy volunteers who had no known systemic disease and who were referred to the hospital for periodic examinations; a pathologist confirmed lung cancer of all patients. All subjects filled out thinformation forms that included age, occupation, and family history, smoking, and alcohol use. Then, $4 \mathrm{cc}$ venous blood sample was obtained from each person. The blood samples were maintained at $-20^{\circ} \mathrm{C}$ until DNA extraction. Genomic DNA was extracted from $200 \mu \mathrm{L}$ peripheral blood using a standard DNA isolation kit (DNPTM, CinnaGen Co, Iran) according to the manufacturer's protocol and stored at $-70^{\circ} \mathrm{C}$ for future using.

\section{rs61764370 Genotype Determination}

PCR-RFLP method was used for rs61764370 genotyping. The forward and reverse primers were $5^{\circ}-\mathrm{GT}$ GTCAGAGTCTCGCTCTTGTC-3' and 5'-AGACCACATAGCACTACCTAAGGA-3 ', respectively. To conduct the PCR reaction, $20 \mathrm{~mL}$, Master mix $(10 \mu \mathrm{l})$, Forward primer $(0.5 \mu \mathrm{l})$, Reverse primer $(0.5 \mu \mathrm{l})$, ddH2O $(8 \mu l)$ and $1 \mu \mathrm{l}$ of genomic DNA were mixed together. Then, the PCR reaction was performed on the Thermosocker in the denaturation stage $\left(95^{\circ} \mathrm{C}\right.$ for two periods of 15 minutes and 10 seconds), annealing $\left(62^{\circ} \mathrm{C}\right.$ for 32 seconds), and an extension stage $\left(72^{\circ} \mathrm{C}\right.$ for 34 seconds) in 32 cycles. To investigate KRAS gene polymorphism (rs61764370), the restriction enzyme Hinf I was used according to the manufacturer's protocol. The results of the Hinf I enzyme digestion were confirmed by direct sequencing (Fig. 1).

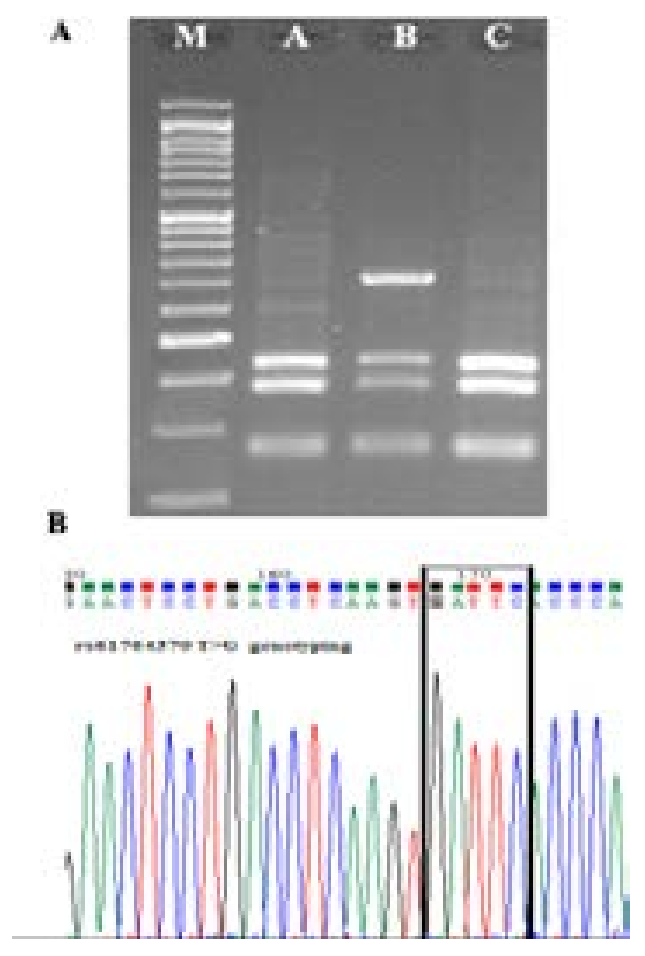

Fig 1. Gel electrophoresis and direct sequencing results.

(A) Gel electrophoresis of PCR products after enzyme digestion,

M: 50bp marker, lanes A and C: Homozygote TT, lane B is TG

heterozygote genotype. (B) Results of direct sequencing of the PCR products. 


\section{Statistical analysis}

Data were analyzed using SPSS version 23. Chi-square and t-test were used to compare the data between the two groups. $\mathrm{P}<0.05$ was considered as significant in all calculations.

\section{Results}

\section{Clinical features of the subjects}

The total number of patients (patients group) and healthy subjects (control group) was 100. The characteristics of the study population are presented in Table 1. The average age of patients group and control group were 52 years (range: 77-35 years) and 61 years (range: 77-34 years), respectively. There was no significant difference between the control group and the patients group in terms of age, sex and cigarette smoking and lung cancer occurrence.

Table 1. Association between rs61764370 polymorphisms and clinicopathological parameters of lung cancer patients.

\begin{tabular}{|c|c|c|c|c|c|c|}
\hline & & \multicolumn{2}{|c|}{ TT } & \multicolumn{2}{|c|}{ TG/GG } & \multirow[t]{2}{*}{ P-value } \\
\hline & & $N$ & $\%$ & $N$ & $\%$ & \\
\hline Patients & & 68 & 68 & 32 & 32 & \\
\hline Age & Median (quartile) & 57.0 & 57 & 63.0 & 63 & 0.21 \\
\hline \multirow[t]{2}{*}{ Gender } & Male & 47 & 47 & 21 & 21 & 0.37 \\
\hline & Female & 21 & 21 & 11 & 11 & \\
\hline \multirow[t]{2}{*}{ Smoking } & Never & 34 & 34 & 24 & 24 & 0.52 \\
\hline & Smokers & 29 & 29 & 13 & 13 & \\
\hline \multirow[t]{4}{*}{ Stage } & I & 15 & 15 & 5 & 5 & 0.76 \\
\hline & II & 19 & 19 & 3 & 3 & \\
\hline & III & 21 & 21 & 9 & 9 & \\
\hline & IV & 13 & 13 & 15 & 15 & \\
\hline \multirow[t]{4}{*}{ Grading } & G1 & 19 & 19 & 6 & 6 & 0.92 \\
\hline & G2 & 25 & 25 & 10 & 10 & \\
\hline & G3 & 15 & 15 & 12 & 12 & \\
\hline & Unknown & 9 & 9 & 4 & 4 & \\
\hline \multirow{5}{*}{ Histotype } & Adenocarcinoma & 59 & 59 & 26 & 26 & 0.63 \\
\hline & Squamous & 3 & 3 & 3 & 3 & \\
\hline & Bronchoalveolar & 2 & 2 & 1 & 1 & \\
\hline & Large cells & 3 & 3 & 1 & 1 & \\
\hline & Other & 1 & 1 & 1 & 1 & \\
\hline
\end{tabular}

The association between the rs61764370 and lung cancer

The genotypic and allelic frequency of KRAS rs61764370 $\mathrm{T}>\mathrm{G}$ polymorphisms is shown in table 2. As shown here, there is a significant difference in the distribution of KRAS rs61764370 polymorphism genotypes between lung cancer patients and controls.
Our results indicate that there is a significant relationship between KRAS gene polymorphism (rs61764370) T $>G$ heterozygote TG genotype vs TT and lung cancer risk $(\mathrm{GG}+\mathrm{GT}$ vs TT: $\mathrm{OR}=6.25,95 \% \mathrm{CI}=2.605$ $15.00, \mathrm{P}=0.000)$. In addition, regarding the comparison between $G$ vs $T$ allele, our analysis indicated that the $G$ allele was a significant risk factor for lung cancer $(\mathrm{OR}=5.252,95 \% \mathrm{CI}=2.259-12.208, \mathrm{P}=0.011)$. 
Table 2. Genotypic and allelic frequencies of rs61764370 polymorphism in lung cancer (case) and control subjects.

\begin{tabular}{lllll}
\hline Genotype & Case (100) & Control (100) & OR and 95\% CI & $\begin{array}{l}\boldsymbol{P} \text { - } \\
\text { Value }\end{array}$ \\
\hline Rs61764370 G>T & & & & \\
TT & $68(68 \%)$ & $93(93 \%)$ & 1 & -- \\
TG & $32(32 \%)$ & $7(7 \%)$ & $6.25(2.60-15.00)$ & 0.000 \\
GG & $0(0 \%)$ & $0(0 \%)$ & --- & -- \\
Allele & & & & \\
T & $168(84 \%)$ & $193(96.5 \%)$ & --- & \\
G & $32(16 \%)$ & $7(3.5 \%)$ & $5.252(2.259-12.208)$ & 0.011 \\
\hline
\end{tabular}

\section{Discussion}

According to the findings of this study, there is a significant relationship between the rs61764370 polymorphism and the risk of lung cancer; the genotype GT (OR: 6.25; 95\% CI $=2.60-15.00$ ) and $\mathrm{G}$ allele (OR: 5.25 ; 95\% CI $=2.259-12.208)$ are significantly associated with an increased risk of lung cancer in the Iranian population. Let-7 is a miRNA with tumor-suppression function and plays an important role in multiple cellular processes such as tumor growth and development ${ }^{19}$. Lower expression of Let 7 is reported in tumor samples of patients with rs61764370 G allele in comparison with $\mathrm{T}$ allele ${ }^{8}$, These findings indicated that rs61764370 $\mathrm{G}$ and $\mathrm{T}$ alleles are associated with expression level of Kras as well as the Let 7 expression ${ }^{20}$.

Chin et al. used a luciferase reporter for KRAS expression to determine the effect of the rs61764370 variants on KRAS expression, they transfected a luciferase reporter with a KRAS 3'UTR containing the variant rs61764370 alleles into A549 cells, they reported a significant increase in luciferase activity in cells transfected with rs61764370 $\mathrm{G}$ allele versus the T allele and they reported an association between the rs $61764370 \mathrm{G}$ allele and increased risk of non-small cell lung cancer (NSCLC) in the Chinese population ${ }^{21}$.

In previous studies, it has been shown that low expression and decreased level of the Let- 7 is associated with different tumors, including lung cancer and the reduc- tion of let-7 expression has been considered as a risk factor for lung cancer. Hollestelle et al. reported that rs61764370 $\mathrm{G}$ allele in the KRAS gene was associated with an increased risk of breast cancer ${ }^{22}$. These findings are consistent with our findings for the Iranian population, on the other hand, Pharoah et al. did not find any association between the rs61764370 genotypes and the risk of ovarian cancer ${ }^{23}$. In a meta-analysis study Zhang et al, reported no significant relationship between rs61764370 polymorphism and lung cancer in the Caucasian population ${ }^{24}$. In previous studies, it has been shown that KRAS variants of RS61764370 interfere with the binding of Let- 7 miRNA and increase the expression of KRAS ${ }^{20}$. This polymorphism was first introduced as a biomarker for lung cancer in the American population $^{21}$.

Due to findings of this study and previous studies and the function of the Let-7 miRNA as a tumor suppressor miRNA, it seems that the presence of the $G$ allele at the Let- 7 binding site blockage Let- 7 binding in this region and results in an increase in the expression of the KARS gene, which can increase the risk of lung cancer.

\section{Conclusion}

We found a significant relationship between the rs6176437, G allele and lung cancer risk in Iranian population and it seems that this polymorphism can be used as a biomarker for lung cancer in the future, however further studies with more samples are recommended to confirm the findings of this study. 


\section{Acknowledgment}

We sincerely thank the human genetic research center of Baqiyatallah University of Medical Sciences for technical and financial support. We would also like to thank Dr. Rouhollah Akbarpour, and Rahim Ramezani for their help with statistical analysis.

\section{Conflict of interest}

None declared.

\section{References}

1- Macdonald F, Ford CHJ, Casson AG, Editors. Molecular biology of cancer. $2^{\text {nd }}$ Ed. Philadelphia: Bios Scientific Publishers; 2005. P.101-104.

2- Siegel R, Naishadham D, Jemal A. Cancer statistics, 2013. CA Cancer J Clin. 2013;63:11 30.

3- Saavedra HI, Knauf JA, Shirokawa JM, Wang J, Ouyang B, Elisei R, et al. The RAS oncogene induces genomic instability in thyroid PCCL3 cells via the MAPK pathway. Oncogene. 2000; 19: 3948-54.

4- Kranenburg O. The KRAS oncogene: past, present, and future. BBA-Rev Cancer. 2005; 1756: 81-2.

5- Kim M, Chen X, Chin L, Paranjape T, Speed W, Kidd $\mathrm{K}$, et al. Extensive sequence variation in the 3' untranslated region of the KRAS gene in lung and ovarian cancer cases. Cell Cycle. 2014; 13: 1030-40.

6- Wahid F, Shehzad A, Khan T, Kim YY. MicroRNAs: synthesis, mechanism, function, and recent clinical trials. Biochim Biophys Acta. 2010; 1803: 1231-1243.

7- Bushati N, Cohen SM. microRNA functions. Annu Rev Cell Dev Biol. 2007; 23: 175-205.

8- Takamizawa J, Konishi H, Yanagisawa K, et al. Reduced expression of the let-7 microRNAs in human lung cancers in association with shortened postoperative survival. Cancer Res. 2004; 64: 3753-6.

9- Li ZH, Pan XM, Han BW, Guo XM, Zhang Z, Jia $\mathrm{J}$, et al. A let-7 binding site polymorphism rs 712 in the KRAS 3' UTR is associated with an increased risk of gastric cancer. Tumour Biology. 2013;34(5):3159-63.

10- Kim M, Chen X, Chin LJ, Paranjape T, Speed WC, Kidd KK, et al. Extensive sequence variation in the 3 ' untranslated region of the KRAS gene in lung and ovarian cancer cases. Cell Cycle. 2014;13(6):1030-40.

11- Pan XM, Jia J, Guo XM, Li ZH, Zhang Z, Qin HJ, et al. Lack of association between let-7 binding site polymorphism rs712 and risk of nasopharyngeal carcinoma. Familial cancer. 2014;13(1):93-7.

12- Johnson SM, Grosshans H, Shingara J, Byrom M, Jarvis R, et al. RAS is regulated by the let-7 microRNA family. Cell. 2005;120:635-47.

13-Paranjape T, Heneghan H, Lindner R, Keane FK,
Hoffman A, et al. A 3'-untranslated region KRAS variant and triplenegative breast cancer: a case-control and genetic analysis. Lancet Oncol. 2011;12:377-86.

14- Takamizawa J, Konishi H, Yanagisawa K, Tomida S, Osada H, et al. Reduced expression of the let-7 microRNAs in human lung cancers in association with shortened postoperative survival. Cancer Res. 2004;64:3753-6. 15- Christensen BC,Moyer BJ, AvissarM, Ouellet LG, Plaza SL, et al. A let-7 microRNA-binding site polymorphism in the KRAS 3'UTR is associated with reduced survival in oral cancers. Carcinogenesis. 2009;30:1003-7.

16- Ratner E, Lu L, Boeke M, Barnett R, Nallur S, et al. A KRAS variant in ovarian cancer acts as a genetic marker of cancer risk. Cancer Res. 2010;70:6509-15.

17- Kjersem JB, Ikdahl T, Guren T, Skovlund E, Sorbye $\mathrm{H}$, Hamfjord J, et al. Let - 1 miRNA-binding site polymorphism in the KRAS 3'UTR; colorectal cancer screening population prevalence and influence on clinical outcome in patients with metastatic colorectal cancer treated with 5-fluorouracil and oxaliplatin +/- cetuximab. BMC Cancer. 2012:12:534-542.

18- Luong HT, Nyholt DR, Painter JN, Chapman B, Kennedy S, Treloar SA, et al. No evidence for genetic association with the let-7 microRNA-binding site or other common KRAS variants in risk of endometriosis. Human Reproduction. 2012;27(12):361 - 366.

19- Lawrie CH, Chi J, Taylor S, Tramonti D, Ballabio E, Palazzo S, Saunders NJ, Pezzella F, Boultwood J, Wainscoat JS, Hatton CS. Expression of microRNAs in diffuse large B cell lymphoma is associated with immunophenotype, survival and transformation from follicular lymphoma. J. Cell. Mol. Med. 2009;13:1248-1260. 20- Xia Y, Zhu Y, Zhou X, Chen Y. Low expression of let-7 predicts poor prognosis in patients with multiple cancers: a meta-analysis. Tumour Biol. 2014;35:51435148.

21- Chin LJ, Ratner E, Leng S, Zhai R, Nallur S, et al. A SNP in a let-7 microRNA complementary site in the KRAS 3'UTR increases nonsmall cell cancer risk. Cancer Res. 2008;68:8535-40.

22- Hollestelle A, Pelletier C, Hooning M, Crepin E, Schutte M, et al. Prevalence of the variant allele rs61764370 T $>\mathrm{G}$ in the 3'UTR of KRAS among Dutch BRCA1, BRCA2 and non-BRCA1/BRCA2 breast cancer families. Breast Cancer Res Treat. 2011;128:79-84.

23. Pharoah PD, Palmieri RT, Ramus SJ, Gayther SA, Andrulis IL, et al. The role of KRAS rs61764370 in invasive epithelial ovarian cancer: implications for clinical testing. Clin Cancer Res. 2011;17: 3742-50.

24- Zhang Sh-Y, Shi J. rs61764370 polymorphism of Kras and risk of cancer in Caucasian population: A meta-analysis. J Can Res Ther . 2016; 12(2): 699-704. 